\title{
Nurse staffing matters: now what?
}

\section{Anne Sales}

Correspondence to

Professor Anne Sales, Department of Systems Leadership and Effectiveness Science (Dept. 2), University of Michigan School of Nursing, Room 4305, 400 North Ingalls Building, Ann Arbor, MI 48109-5482, USA; salesann@umich.edu

Accepted 9 February 2015

\section{SLinked}

- http://dx.doi.org/10.1136/ bmjqs-2014-003346

\section{CrossMark}

To cite: Sales A. BMJ Qual Saf 2015;24:241-243.
Brooks Carthon and colleagues ${ }^{1}$ assess the relationship between the quality of hospital work environments for registered nurses and 'missed care' reported by nurses. Similar to other authors, they define missed care as care that nurses regarded as necessary but left undone due to a lack of time. $^{2-4}$ Brooks Carthon and colleagues ${ }^{1}$ also explore the relationship between both of these variables and hospital readmissions for heart failure. Their analysis represents an important step in moving beyond the literature describing relationships between nurse staffing and patient outcomes. ${ }^{5-7}$

For patients with heart failure in the large sample of hospitals included in their secondary analysis, Brooks Carthon et al ${ }^{1}$ find that nurses' self-report of missing important elements of care correlates with readmissions in this group of ill, vulnerable patients. For 4 of the 10 nursing activities they studied, each 10-percentage-point increase in the number of nurses reporting having missed the activity was associated with an increase in the odds of readmission by $2 \%-8 \%$ after adjusting for patient and hospital characteristics. Interestingly, they also showed that missed nursing care no longer predicted readmission once adjusting for the nurse work environment, except in the case of the delivery of treatments and procedures (as opposed to processes of care such as care planning, care coordination, talking to or comforting patients, among others).

Caveats to this approach to the study of complex phenomena include the following: the use of administrative data not originally collected for research purposes, which may not adequately adjust both for risk and severity of illness; the necessity of conducting the analysis at the hospital level when nursing units are more proximal, with shift-level detail likely needed to establish causality; ${ }^{8}{ }^{9}$ and lack of a clear link between the nurses who provide care and patients who receive it. ${ }^{10}$ These important issues notwithstanding the question addressed in this paper-what is it about staffing levels that makes a difference-move us beyond simply discussing a factor that many hospitals and health systems cannot easily change in the short term to a question about how we might modify the work environment, together with staffing changes, to enable nurses to deliver more of the essential care that matters to patient outcomes.

However, this study only opens the discussions needed to move towards real solutions to the problems that cause poor outcomes for patients, including readmission for heart failure, and other possibly more tractable issues. Work environment may well provide one key to making it possible for nurses to attend to care coordination and other essential activities, but other approaches are more actionable. In particular, two programmes focused on nurses and their ability to use their time productively to provide high-quality patient care are worth focusing on.

First, the Transforming Care at the Bedside programme, funded initially by the Robert Wood Johnson Foundation and managed in conjunction with the Institute for Healthcare Improvement, was deployed initially as a pilot in 13 sites, then adopted at least in part by a larger number of hospitals across the USA. ${ }^{8}{ }^{11-15}$ Although no longer funded as an initiative, elements of the programme remain in place at some hospitals. In the pilot sites, where the programme was implemented with considerable care and resources were available for implementation, the effect was widely perceived as positive.

Second, the Productive Ward or Releasing Time to Care initiative in the English National Health Service used similar concepts and approaches, based largely on Lean principles, to improve nurses' morale and productivity with respect to patient care. $^{16-21}$ In many ways similar to Transforming Care at the Bedside, the Productive Ward programme invests in frontline nurses, empowering them to direct the way their work effort is used.

We must move beyond descriptive studies and correlational analyses to 
ensuring that we understand the causal paths by which hospitals and their largest workforce can improve care that patients receive. The solutions may not always lie in more staffing, particularly among the most professional groups, such as baccalaureate prepared registered nurses, but instead in creative approaches to allowing these professionals to direct their own work and to recommend staffing and skill mix for their units. The solutions probably do not lie solely in the professional nursing workforce, but also in the support staff who provide critically important services under the direction of professional nurses. In work in which we are currently engaged, an approach by the Veterans Health Administration's Office of Nursing Services to empower frontline nurses to participate in recommending appropriate levels of staffing and skill mix shows some promise in supporting improved work environments. ${ }^{22}$

In addition to the general methodological concerns noted earlier, an additional note of caution is warranted about inferences from the work reported by Brooks Carthon et al. ${ }^{1}$ Focusing on readmissions for patients with heart failure has the merit of obvious policy relevance, as hospitals face penalties if they cannot reduce readmissions among these patients. However, a substantial proportion of hospitalised patients with heart failure are in fact at the end of their lives, with relatively little possibility of staying out of the hospital, particularly when alternative services for high-quality end of life care are not readily available to them. ${ }^{23}$ Given this, and the fact that in a secondary analysis conducted at the hospital level, the authors were not able to separate out those patients for whom preventing readmission is a realistic goal, readers should interpret the findings with caution.

The results reported by Brooks Carthon et $a l^{1}$ are intriguing and in that they point to new directions for a voluminous but to a great extent stagnant literature. However, assuming that patients with heart failure are necessarily the first group that we should target for changes in care coordination may lead to considerable difficulty, replicating these findings with higher quality prospective studies. Other groups of patients, and outcomes other than readmission, may benefit as much or more than this initial group. Nonetheless, this type of analysis represents an important advance in so far as it takes us beyond the well-established link between nurse staffing and patient outcomes, exploring the mechanisms underlying these associations (missed care likely being one of them) and the degree to which nursing environments can mitigate or these associations.

\section{Competing interests None.}

Provenance and peer review Not commissioned; internally peer reviewed.

\section{REFERENCES}

1 Brooks Carthon JM, Lasater KB, Sloane DM, et al. The quality of hospital work environments and missed nursing care are linked to heart failure readmissions: a cross sectional study of U.S. hospitals. BMJ Qual Saf 2015;24:255-63.

2 Ausserhofer D, Zander B, Busse R, et al. Prevalence, patterns and predictors of nursing care left undone in European hospitals: results from the multicountry cross-sectional RN4CAST study. BMJ Qual Saf 2014;23:126-35.

3 Ball JE, Murrells T, Rafferty AM, et al. 'Care left undone' during nursing shifts: associations with workload and perceived quality of care. BMJ Qual Saf 2014;23:116-25.

4 Wakefield BJ. Facing up to the reality of missed care. BMJ Qual Saf 2014;23:92-4.

5 Shekelle PG. Nurse-patient ratios as a patient safety strategy: a systematic review. Ann Intern Med 2013;158:404-9.

6 Needleman J, Buerhaus P, Mattke S, et al. Nurse-staffing levels and the quality of care in hospitals. N Engl J Med 2002;346:1715-22.

7 Aiken LH, Clarke SP, Sloane DM, et al. Hospital nurse staffing and patient mortality, nurse burnout, and job dissatisfaction. JAMA 2002;288:1987-93.

8 Needleman J, Buerhaus P, Pankratz VS, et al. Nurse staffing and inpatient hospital mortality. $N$ Engl J Med 2011;364:1037-45.

9 Sales A, Sharp N, Li YF, et al. The association between nursing factors and patient mortality in the Veterans Health Administration: the view from the nursing unit level. Med Care 2008;46:938-45.

10 Yakusheva O, Lindrooth R, Weiss M. Nurse value-added and patient outcomes in acute care. Health Serv Res 2014;49:1767-86.

11 Needleman J, Hassmiller S. The role of nurses in improving hospital quality and efficiency: real-world results. Health Aff 2009;28:w625-33.

12 Yee T, Needleman J, Pearson M, et al. Nurse manager perceptions of the impact of process improvements by nurses. J Nurs Care Qual 2011;26:226-35.

13 Parkerton PH, Needleman J, Pearson ML, et al. Lessons from nursing leaders on implementing TCAB. Am J Nurs 2009;109:71-6.

14 Pearson ML, Needleman J, Parkerton PH, et al. Participation of unit nurses: front-line implementation on TCAB pilot units. Am J Nurs 2009;109:66-70.

15 Needleman J, Parkerton PH, Pearson ML, et al. Overall effect of TCAB on initial participating hospitals. Am J Nurs 2009;109:59-65.

16 Morrow E, Robert G, Maben J. Exploring the nature and impact of leadership on the local implementation of the Productive Ward Releasing Time to Care. J Health Organ Manag 2014;28:154-76.

17 Morrow E, Robert G, Maben J, et al. Implementing large-scale quality improvement: lessons from The Productive Ward: Releasing Time to Care. Int J Health Care Qual Assur 2012;25:237-53.

18 Van Bogaert P, Clarke S, Willems R, et al. Staff engagement as a target for managing work environments in psychiatric hospitals: implications for workforce stability and quality of care. J Clin Nurs 2013;22:1717-28.

19 Van Bogaert P, Clarke S, Wouters K, et al. Impacts of unit-level nurse practice environment, workload and burnout on nurse-reported outcomes in psychiatric hospitals: a multilevel modelling approach. Int J Nurs Stud 2013;50:357-65.

20 Van Bogaert P, Van Heusden D, Somers A, et al. The Productive Ward program: a longitudinal multilevel study of nurse perceived practice environment, burnout, and 
nurse-reported quality of care and job outcomes. J Nurs Adm 2014;44:452-61.

21 Van Bogaert P, Wouters K, Willems R, et al. Work engagement supports nurse workforce stability and quality of care: nursing team-level analysis in psychiatric hospitals. J Psychiatr Ment Health Nurs 2013;20:679-86.
22 Taylor B, Yankey N, Robinson C, et al. Evaluating the Veterans Health Administration's Staffing Methodology model: a reliable approach. Nurs Econ 2015;33:36-40, 66.

23 Whellan DJ, Goodlin SJ, Dickinson MG, et al. End-of-life care in patients with heart failure. J Card Fail 2014;20:121-34. 